\title{
THE ANTIOXIDANT PROPERTIES OF CARNITINE in vitro
}

\author{
KATARZYNA SOLARSKA ${ }^{1}$, ANNA LEWIŃSKA ${ }^{1}$, AGATA \\ KAROWICZ-BILIŃSKA ${ }^{2}$ and GRZEGORZ BARTOSZ ${ }^{1,3^{*}}$
}

${ }^{1}$ Department of Biochemistry and Cell Biology, University of Rzeszów, Pigonia 6, 35-959 Rzeszów, Poland, ${ }^{2}$ Clinic of High-Risk Pregnancy, Medical University

of Łódź, Wileńska 37, 94-029 Łódź, Poland, ${ }^{3}$ Department of Molecular

Biophysics, University of Łódź, Banacha 12/16, 90-237 Łódź, Poland

\begin{abstract}
Many of the effects of carnitine are ascribed to its antioxidant properties. The aim of this study was to evaluate the antioxidant properties of carnitine in vitro. Carnitine was found to decolorize $\mathrm{ABTS}^{\bullet+}$, and to protect fluorescein against bleaching induced by AAPH-derived peroxyl radicals and peroxynitrite, thiol groups against oxidation induced by hydrogen peroxide, peroxyl radicals, hypochlorite and peroxynitrite, and erythrocytes against hemolysis induced by peroxyl radicals and hypochlorite. These results show that carnitine has a direct antioxidant action against physiologically relevant oxidants.
\end{abstract}

Key words: Antioxidant, Carnitine, Hydrogen peroxide, Hypochlorite, Peroxyl radical, Peroxynitrite

\section{INTRODUCTION}

L-Carnitine ( $\beta$-hydroxy- $\gamma$-4- $n$-trimethylaminobutyric acid) is an important metabolite that performs many functions in the body. Its main metabolic role is the transport of long-chain fatty acids into the mitochondrial matrix across the inner mitochondrial membrane. It is also a cofactor in the peroxisomal oxidation of very long-chain fatty acids, and it plays a role in the central nervous system,

* Author for correspondence. e-mail: gbartosz@biol.uni.lodz.pl, tel./fax: +48 426354476

Abbreviations used: AAPH - 2,2'-azobis(2-amidinopropane) dihydrochloride; ABTS 2,2'-azino-bis(3-ethylbenzthiazoline-6-sulfonate); DTNB - 5,5'-dithio-bis(2-nitrobenzoic acid); PBS - phosphate-buffered saline 
mediating the transfer of acetyl groups for acetylcholine synthesis and affecting signal transduction pathways and gene expression. It intensifies respiration and peroxisome function and is often used as a food additive supposed to increase physical performance $[1,2]$, promote weight loss [3, 4] and increase reproductive performance $[5,6]$. It has been also found to improve immunological functions $[7,8]$ and is suggested to be a therapeutic agent for several neurodegenerative disorders $[9,10]$.

The beneficial effects of carnitine appear to be mediated, at least in part, by its antioxidant properties, which include the upregulation of the level of glutathione $[8,9]$ and the elevation of the activities of antioxidant enzymes [8]. The in vivo effects may be mediated by the direct antioxidant action of carnitine or by its effects on the biosynthesis of antioxidant enzymes and other proteins. In this context, it is of interest to characterize the antioxidant properties of carnitine in well-defined systems in vitro, as this may contribute to the elucidation of the mechanisms of the antioxidant action of this compound. Previous studies have demonstrated that carnitine reacts with superoxide and hydrogen peroxide, has reducing properties, chelates iron, and prevents lipid peroxidation and DNA cleavage $[11,12]$. The aim of this study was to further characterize the antioxidant properties of carnitine in vitro, particularly with regard to pathophysiologically relevant oxidants such as peroxynitrite and hypochlorite. These oxidants are not neutralized enzymatically in vivo, so low-molecular weight antioxidants that would protect against their action would be even more important than ones protecting against superoxide or hydrogen peroxide, which are removed enzymatically.

\section{MATERIALS AND METHODS}

\section{Reagents}

The reagents were obtained from Sigma/Aldrich (Poznań, Poland) unless stated otherwise. Peroxynitrite was synthesized from sodium azide and ozone according to the method of Pryor et al. [13] with minor modifications [14]. This method yields low ionic strength peroxynitrite that does not contain hydrogen peroxide as an impurity. Briefly, an ozone stream from an ozonator $(75 \mu \mathrm{g} / \mathrm{ml}$ in oxygen, $100 \mathrm{ml} / \mathrm{min}$ ) was bubbled for about $60 \mathrm{~min}$ through a glass-frit into $100 \mathrm{ml}$ of $0.2 \mathrm{M}$ sodium azide in water that had had its $\mathrm{pH}$ adjusted to 12 with $1 \mathrm{~N} \mathrm{NaOH}$ and had been chilled to $0^{\circ} \mathrm{C}$ in an ice-water mixture. The final concentration of peroxynitrite was about $70-90 \mathrm{mM}$. Stock solutions were stored at $-85^{\circ} \mathrm{C}$ and used within 4-6 weeks after synthesis. Before each experiment, the concentration of peroxynitrite was estimated spectrophotometrically at $302 \mathrm{~nm}$ in $0.1 \mathrm{M} \mathrm{NaOH}$ $\left(\varepsilon_{\mathrm{M}}=1670 \mathrm{M}^{-1} \mathrm{~cm}^{-1}\right)$.

\section{Reactivity with ABTS $^{\bullet+}$}

We used a slight modification [15] of the methods of decolorization of the $\mathrm{ABTS}^{\bullet+}$ radical [16]. $\mathrm{ABTS}^{\bullet+}$ was prepared via a reaction of $19.5 \mathrm{mg}$ of 
ammonium 2,2'-azino-bis(3-ethylbenzthiazoline-6-sulfonate) with $3.3 \mathrm{mg}$ of potassium persulfate in $7 \mathrm{ml}$ of $100 \mathrm{mM}$ sodium phosphate buffer, $\mathrm{pH} 7.4$, for 12 to $16 \mathrm{~h}$ in the dark. The thus-obtained dark blue-green solution of ABTS ${ }^{\bullet+}$ was aliquoted and kept frozen at $-20^{\circ} \mathrm{C}$ until use. The aliquots were thawed and diluted with the same buffer to give an absorbance of 1.0 at $414 \mathrm{~nm}$ immediately before use. Aliquots of solutions of the tested compounds $(10 \mu \mathrm{l})$ in the phosphate buffer were mixed rapidly with $990 \mu$ of the diluted $\mathrm{ABTS}^{\bullet+}$ solution in a spectrophotometric cuvette, and the absorbance was measured exactly $3 \mathrm{~min}$ after mixing the antioxidant(s) with the $\mathrm{ABTS}^{\bullet+}$ solution.

\section{The protection of fluorescein against oxidant-induced bleaching}

Fluorescein $(2 \mu \mathrm{M})$ in $100 \mathrm{mM}$ phosphate buffer, $\mathrm{pH} 7.4$, was mixed in the presence or absence of the tested antioxidants, with oxidants, namely $20 \mu \mathrm{M}$ $\mathrm{HOCl}, \mathrm{ONOO}^{-}$or $10 \mathrm{mM}$ AAPH (final concentrations), in a final volume of $1 \mathrm{ml}$. The fluorescence of the samples was measured at the excitation/emission wavelengths of $480 \mathrm{~nm} / 514 \mathrm{~nm}$ in a Hitachi F-2500 spectrofluorimeter after a 15-min incubation with $\mathrm{HOCl}$ or $\mathrm{ONOO}^{-}$at room temperature, or after a 60 -min incubation with $\mathrm{AAPH}$ at $37^{\circ} \mathrm{C}$. The results were analyzed in a way analogous to that presented by Kohri et al. [17] by plotting $\Delta \mathrm{F} / \Delta \mathrm{F}_{\mathrm{o}}-1$ vs the concentration of the antioxidant, where $\Delta \mathrm{F}$ is the decrease in fluorescence induced by an oxidant in the presence of a given concentration of that antioxidant, and $\Delta \mathrm{F}_{\mathrm{o}}$ is the decrease in fluorescence induced by the same amount of the oxidant in the absence of an antioxidant. The initial part of this curve is linear (Robaszkiewicz et al., submitted).

\section{The protection of thiol groups against oxidation}

Glutathione solution $(250 \mu \mathrm{M}$, final) in phosphate-buffered saline $(145 \mathrm{mM}$

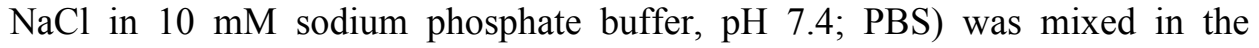
presence or absence of the tested antioxidants, with oxidants, namely $0.5 \mathrm{mM}$ $\mathrm{H}_{2} \mathrm{O}_{2}, 10 \mathrm{mM}$ AAPH, $375 \mu \mathrm{M} \mathrm{HOCl}$ or $500 \mu \mathrm{M} \mathrm{ONOO}^{-}$(final concentrations) to make up a volume of $500 \mu \mathrm{l}$. After a 15 -min incubation at room temperature (hypochlorite and peroxynitrite) or a 1-h incubation at $37^{\circ} \mathrm{C}\left(\mathrm{H}_{2} \mathrm{O}_{2}, \mathrm{AAPH}\right)$, the samples were diluted with $1 \mathrm{ml}$ of $0.1 \mathrm{M}$ phosphate buffer, $\mathrm{pH} 8.0$, and added

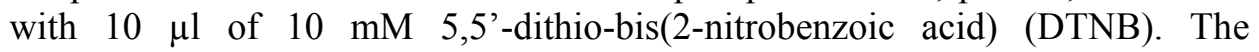
absorbance of the thionitrobenzoic acid was measured at $412 \mathrm{~nm}$.

\section{The protection of erythrocytes against oxidant-induced hemolysis}

Aliquots of erythrocyte suspensions in phosphate-buffered saline containing no oxidant or supplemented with antioxidants were added with an oxidant $(30 \mathrm{mM}$ AAPH or $375 \mu \mathrm{M}$ hypochlorite) to a final volume of $200 \mu 1$. The changes in their turbidance were measured at $600 \mathrm{~nm}$ in an Anthos 2010 absorbance reader after a 15 -min incubation at room temperature for hypochlorite, or after various times of incubation at $37^{\circ} \mathrm{C}$ for AAPH. The initial concentration of erythrocytes was chosen to provide an initial turbidance for the suspension of 1.0. All the presented results are mean values from at least 3 independent experiments. 


\section{RESULTS AND DISCUSSION}

Carnitine reduced $\mathrm{ABTS}^{\bullet+}$ like other antioxidants and was 3.6-fold less efficient than Trolox in this reaction (Fig. 1). Carnitine did not exhibit any reactivity in the FRAP assay (giving values lower than the reagent blank), in agreement with its reported ability to chelate iron ions [11].

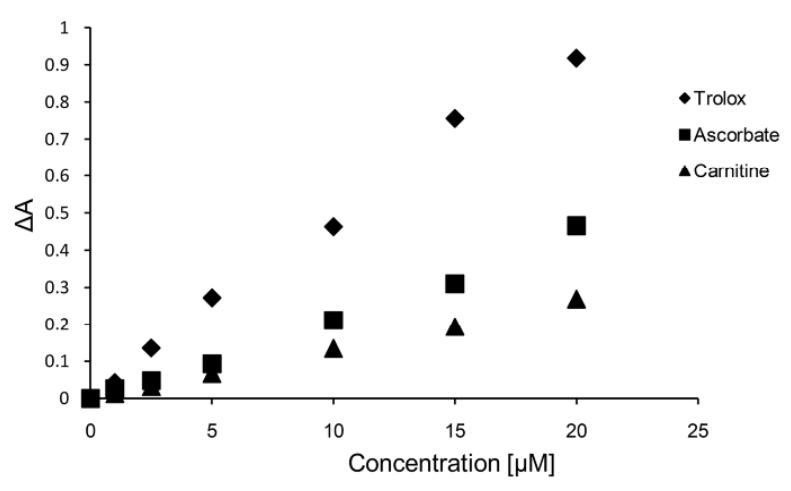

Fig. 1. The reactivity of carnitine in the $\mathrm{ABTS}^{\bullet+}$ decolorization assay. The decrease in the absorbance of preformed $\mathrm{ABTS}^{\bullet+}$ due to antioxidants was measured at $414 \mathrm{~nm}$ after $3 \mathrm{~min}$ of reaction.

$\mathrm{ABTS}^{\bullet+}$, although widely used in studies of antioxidant activity, is a promiscuous and not a naturally occurring radical. The reactivity of carnitine against more relevant oxidants is therefore even more interesting. We compared the reactivities of carnitine and standard antioxidants with respect to other oxidants. Carnitine effectively protected fluorescein against bleaching induced by hypochlorite, peroxynitrite and peroxyl radicals derived from the commonly used azo initiator, 2,2'-azobis(2-amidinopropane) dihydrochloride (AAPH),
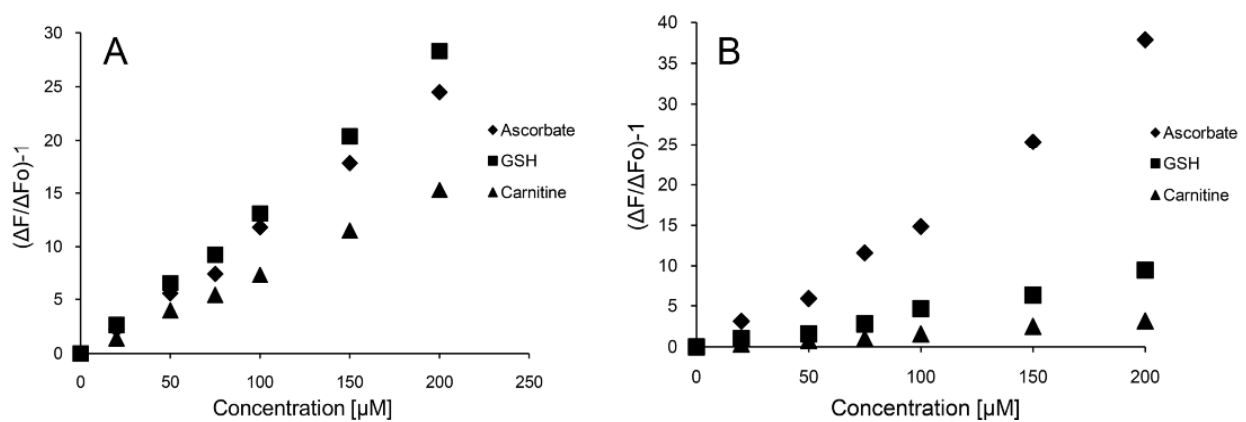

Fig. 2. The protection of fluorescein against AAPH-induced (A) and peroxynitrite-induced bleaching (B) by antioxidants. Fluorescein $(2 \mu \mathrm{M})$ reacted with AAPH $(10 \mathrm{mM})$ at $37^{\circ} \mathrm{C}$ for $1 \mathrm{~h}$ or with $20 \mu \mathrm{M}$ peroxynitrite at room temperature for 15 minutes in $0.1 \mathrm{M}$ sodium phosphate, $\mathrm{pH} 7.4$, in the absence or in the presence of antioxidants at various concentrations. The decreases in fluorescence $\left(\Delta \mathrm{F}_{\mathrm{o}}\right.$ and $\Delta \mathrm{F}$, respectively) were measured at $480 \mathrm{~nm} / 514 \mathrm{~nm}$. 
although its protective activity against peroxynitrite was distinctly lower with respect to ascorbate and glutathione (Fig. 2). Surprisingly, in contrast to glutathione and ascorbate, carnitine was unable to protect against hypochloriteinduced fluorescein bleaching, even slightly enhancing the loss of fluorescence evoked by hypochlorite (not shown).

Another test reaction for antioxidant activity was assessing the protection of thiol groups against oxidation induced by oxidants. In this system, carnitine protected thiol groups against oxidation induced by hydrogen peroxide, AAPH, hypochlorite and peroxynitrite. It was more effective than Trolox at protecting against AAPH-derived radicals and hypochlorite (Fig. 3).
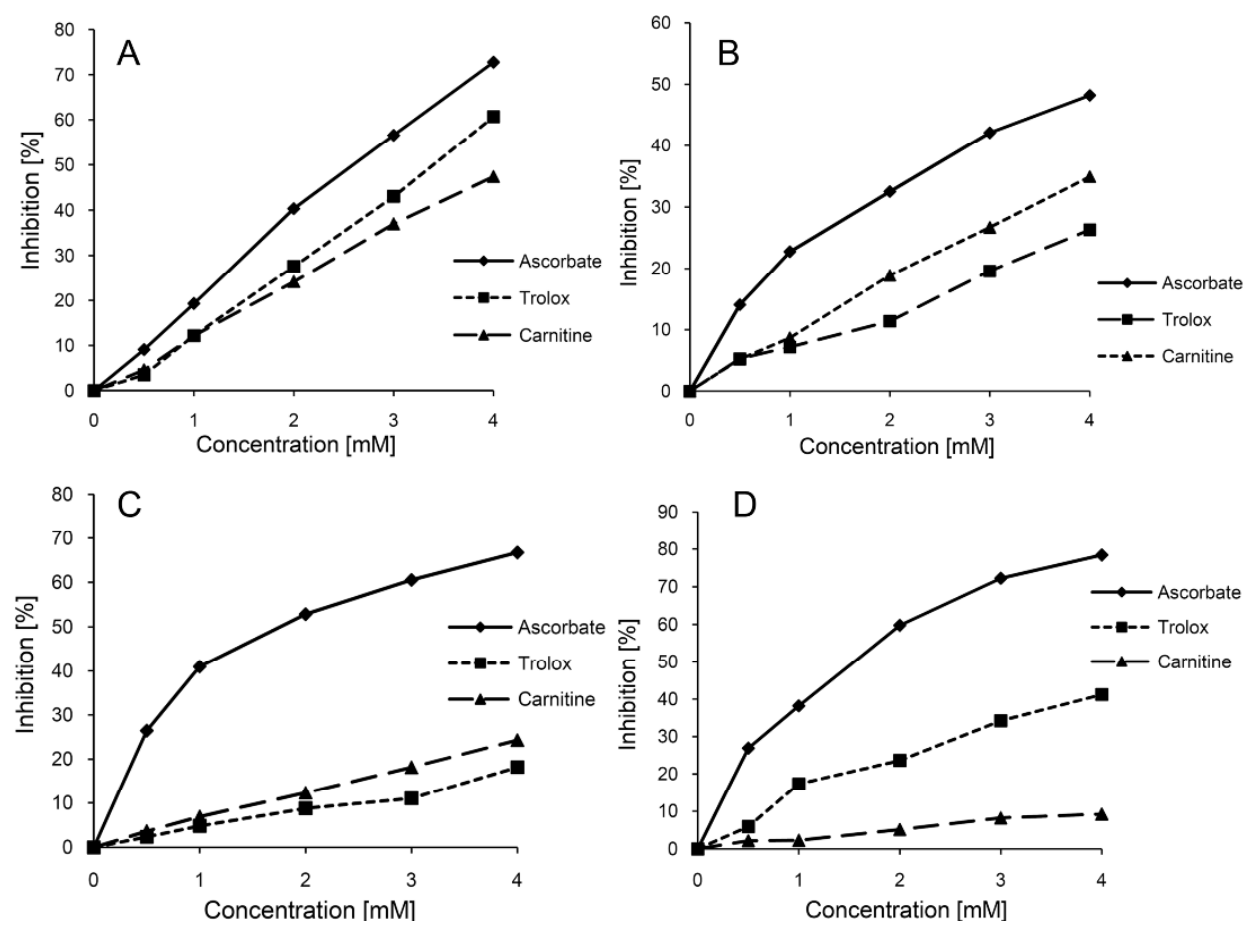

Fig. 3. The inhibition of the $\mathrm{H}_{2} \mathrm{O}_{2-}$ (A), AAPH- (B), hypochlorite- (C) and peroxynitriteinduced (D) thiol group oxidation of glutathione by antioxidants. Glutathione $(250 \mu \mathrm{M})$ in PBS, pH 7.4, was incubated with $0.5 \mathrm{mM}$ hydrogen peroxide, $10 \mathrm{mM}$ AAPH, $375 \mu \mathrm{M}$ $\mathrm{HOCl}$ or $500 \mu \mathrm{M} \mathrm{ONOO}^{-}$(final) in the absence and presence of antioxidants at $37^{\circ} \mathrm{C}$ for $1 \mathrm{~h}(\mathrm{~A}, \mathrm{~B})$ or $15 \mathrm{~min}$ at room temperature $(\mathrm{C}, \mathrm{D})$. The concentration of -SH groups was then determined immediately with Ellman reagent. In the absence of antioxidants, $90.1 \%$ (A), $63 \%$ (B), $72.6 \%$ (C) and $48.6 \%$ (D) of the thiol groups were oxidized.

Treating erythrocytes with oxidants induces hemolysis, which can be easily monitored turbidimetrically in a plate reader, and which is prevented by antioxidants. In this system, carnitine protected erythrocytes against lysis induced by AAPH and hypochlorite (Fig. 4). 

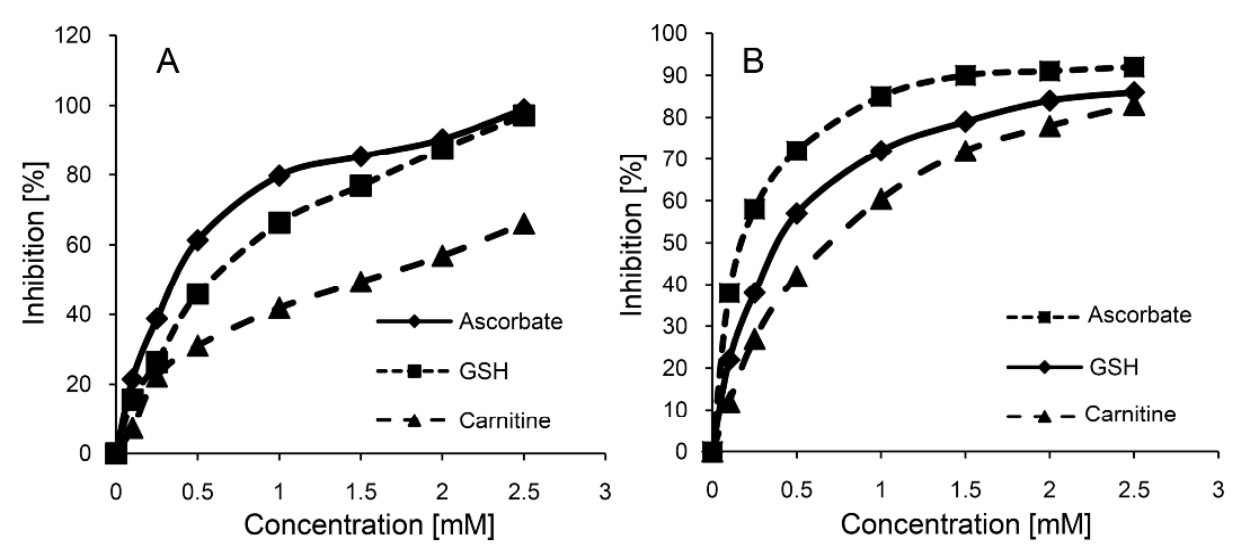

Fig. 4. The protection of erythrocytes against AAPH- (A) and hypochlorite-induced (B) hemolysis by antioxidants. Erytrocytes were incubated in PBS with $30 \mathrm{mM}$ AAPH at $37^{\circ} \mathrm{C}$ for $4 \mathrm{~h}$ (A) or with $375 \mu \mathrm{M}$ hypochlorite for $15 \mathrm{~min}(\mathrm{~B})$, and hemolysis was evaluated by assessing the decrease in the turbidity of the suspension at $600 \mathrm{~nm}$. The turbidance of the control samples was 1 , that of the AAPH-treated samples without antioxidants was 0.45 , and that of the hypochlorite-treated samples without antioxidants was 0.22 .

It has been demonstrated by other authors that L-carnitine reacts with superoxide and hydrogen peroxide. It has reducing activity comparable to that of the 1,1-diphenyl-2-picryl-hydrazyl (DPPH) stable free radical and ferricyanide ion. This compound protects linoleic acid against autoxidation and peroxidation induced by UV-photolysis of $\mathrm{H}_{2} \mathrm{O}_{2}$, and pBR322 plasmid DNA against cleavage induced by UV-photolysis. It is an efficient scavenger of ferrous ions, more potent than ferrozine $[11,12]$.

The results of this study fully confirm previous findings on the antioxidant properties of carnitine in vitro. In specific cases (viz. fluorescein oxidation by hypochlorite), the possibility of aggravating damage cannot be excluded (as with any antioxidant). A similar pro-oxidant effect of carnitine has been reported under specific conditions of microsomal lipid peroxidation [18].

The relative reactivity of carnitine with respect to the tested reference antioxidants was different for the various systems, which is understandable taking into account the complexity of antioxidant action. I. a., antioxidants may react directly with oxidants, break oxidant-induced reactions, or repair oxidatively damaged molecules [19]. The contributions of these effects may be different in different systems. This study expands on previous findings by demonstrating the ability of carnitine to counteract the oxidative effects of the physiologically relevant oxidants: hydrogen peroxide, peroxyl radicals, hypochlorite and peroxynitrite.

Acknowledgements. This study was performed within the framework of COST B35 and supported by grant-in-aid No. 83/N-Cost/2007/0. 


\section{REFERENCES}

1. Benvenga, S. Effects of L-carnitine on thyroid hormone metabolism and on physical exercise tolerance. Horm. Metab. Res. 37 (2005) 566-571.

2. Kraemer, W.J., Volek, J.S. and Dunn-Lewis, C. L-carnitine supplementation: influence upon physiological function. Curr. Sports Med. Rep. I (2008) 218-223.

3. Brandsch, C. and Eder, K. Effect of L-carnitine on weight loss and body composition of rats fed a hypocaloric diet. Ann. Nutr. Metab. 46 (2002) 205-210.

4. Elmslie, J.L., Porter, R.J., Joyce, P.R., Hunt, P.J. and Mann, J.I. Carnitine does not improve weight loss outcomes in valproate-treated bipolar patients consuming an energy-restricted, low-fat diet. Bipolar Disord. $\underline{8}$ (2006) 503507.

5. Brandsch, C. and Eder, K. Reproductive performance of rats supplemented with L-carnitine. J. Anim. Physiol. Anim. Nutr. (Berl). 87 (2003) 301-308.

6. Zhou, X., Liu, F. and Zhai, S. Effect of L-carnitine and/or L-acetyl-carnitine in nutrition treatment for male infertility: a systematic review. Asia Pac. J. Clin. Nutr. 16, Suppl 1 (2007) 383-390.

7. De Simone, C., Tzantzoglou, S., Famularo, G., Moretti, S., Paoletti, F., Vullo, V. and Delia, S. High dose L-carnitine improves immunologic and metabolic parameters in AIDS patients. Immunopharmacol. Immunotoxicol. 15 (1993) 1-12.

8. Thangasamy, T., Jeyakumar, P., Sittadjody, S., Joyee, A.G. and Chinnakannu, P. L-Carnitine mediates protection against DNA damage in lymphocytes of aged rats. Biogerontology 10 (2009) 163-172.

9. Calabrese, V., Colombrita, C., Sultana, R., Scapagnini, G., Calvani, M., Butterfield, D.A. and Stella, A.M. Redox modulation of heat shock protein expression by acetylcarnitine in aging brain: relationship to antioxidant status and mitochondrial function. Antioxid. Redox Signal. $\underline{8}$ (2006) 404-416.

10. Calabrese, V., Cornelius, C., Mancuso, C., Barone, E., Calafato, S., Bates, T., Rizzarelli, E. and Kostova, A.T. Vitagenes, dietary antioxidants and neuroprotection in neurodegenerative diseases. Front. Biosci. 14 (2009) 376-397.

11. Gulcin, I. Antioxidant and antiradical activities of L-carnitine. Life Sci. $\underline{78}$ (2006) 803-811.

12. Vanella, A., Russo, A., Acquaviva, R., Campisi, A., Di Giacomo, C., Sorrenti, V. and Barcelona, M.L. L-Propionyl-carnitine as superoxide scavenger, antioxidant, and DNA cleavage protector. Cell Biol. Toxicol. $\underline{16}$ (2000) 99-104.

13. Pryor, W.A., Cueto, R., Jin, X., Koppenol, W.H., Ngu-Schwemlein, M., Squadrido, G., Uppu, P.L. and Uppu, R.M. A practical method for preparing peroxynitrite solutions of low ionic strength and free of hydrogen peroxide.

Free Radic. Biol. Med. 18 (1995) 75-83. 
14. Soszynski, M. and Bartosz, G. Effect of peroxynitrite on erythrocytes. Biochim. Biophys. Acta 1291 (1996) 107-114.

15. Balcerczyk, A., Sowa, K. and Bartosz, G. Metal chelators react also with reactive oxygen and nitrogen species. Biochem. Biophys. Res. Commun. $\underline{352}$ (2007) 522-525.

16. Re, R., Pellegrini, N., Proteggente, A., Pannala, A., Yang, M. and RiceEvans, C. Antioxidant activity applying an improved ABTS radical cation decolorization assay. Free Radic. Biol. Med. 26 (1999) 1231-1237.

17. Kohri, S., Fujii, H., Oowada, S., Endoh, N., Sueishi, Y., Kusakabe, M., Shimmei, M. and Kotake, Y. An oxygen radical absorbance capacity-like assay that directly quantifies the antioxidant's scavenging capacity against AAPH-derived free radicals. Anal. Biochem. 386 (2009) 167-171.

18. Hu, M.L., Chen, Y.K. and Lin, Y.F. The antioxidant and prooxidant activity of some B vitamins and vitamin-like compounds. Chem. Biol. Interact. 97 (1995) 63-73.

19. Kirsch, M. and de Groot, $\mathrm{H}$. NAD $(\mathrm{P}) \mathrm{H}$, a directly operating antioxidant? FASEB J. 15 (2001) 1569-1574. 